\title{
BMJ Open Gender disparities in first medical contact and delay in ST-elevation myocardial infarction: a prospective multicentre Swedish survey study
}

\author{
Sofia Sederholm Lawesson,, ${ }^{1,2}$ Rose-Marie Isaksson,, ${ }^{3,4}$ Maria Ericsson, ${ }^{1}$ \\ Karin Ängerud, ${ }^{5,6}$ Ingela Thylén, ${ }^{1}$ On behalf of the SymTime Study Group
}

To cite: Sederholm Lawesson S, Isaksson R-M, Ericsson M, et al. Gender disparities in first medical contact and delay in ST-elevation myocardial infarction: a prospective multicentre Swedish survey study. BMJ Open 2018;8:e020211. doi:10.1136/ bmjopen-2017-020211

- Prepublication history for this paper is available online. To view these files, please visit the journal online (http://dx.doi. org/10.1136/bmjopen-2017020211).

Received 23 October 2017 Revised 9 March 2018 Accepted 15 March 2018

Check for updates

${ }^{1}$ Department of Cardiology and Department of Medical and Health Sciences, Linköping University, Linköping, Sweden ${ }^{2}$ Department of Medicine, Stanford Prevention Research Center, CA, United States ${ }^{3}$ Department of Research, Norrbotten County Council, Luleå, Sweden

${ }^{4}$ Division of Nursing Sciences, Department of Medicine and Health Sciences, Linköping University, Linköping, Sweden ${ }^{5}$ Department of Nursing, Umeå University, Umeå, Sweden

${ }^{6}$ Cardiology, Heart Centre, Umeå University, Umeå, Sweden

Correspondence to

Dr Sofia Sederholm Lawesson; sofia.lawesson@liu.se

\section{ABSTRACT}

Objectives Compare gender disparities in ST-elevation myocardial infarction (STEMI) regarding first medical contact (FMC) and prehospital delay times and explore factors associated with prehospital delay in men and women separately.

Design Cross-sectional study based on medical records and a validated questionnaire. Eligible patients were enrolled within 24 hours after admittance to hospital. Setting Patients were included from November 2012 to January 2014 from five Swedish hospitals with catheterisation facilities 24/7.

Participants 340 men and 109 women aged between 31 and 95 years completed the survey.

Main outcome measures FMC were divided into five possible contacts: primary healthcare centre by phone or directly, national advisory nurse by phone, emergency medical services (EMS) and emergency room directly. Two parts of prehospital delay times were studied: time from symptom onset to FMC and time from symptom onset to diagnostic ECG. Results Women more often called an advisory nurse as FMC ( $28 \%$ vs $18 \%, p=0.02)$. They had a longer delay until FMC, 90 (IQR 39-221) vs 66 (28-161) min, $p=0.04$ and until ECG, 146 (68-316) vs 103 (61-221) min, $p=0.03$. Men went to hospital because of believing they were stricken by an MI to a higher extent than women did $(25 \%$ vs $15 \%, p=0.04$ ) and were more often recommended to call EMS by bystanders ( $38 \%$ vs $22 \%, p<0.01)$. Hesitating about going to hospital and experiencing pain in the stomach/back/shoulders were factors associated with longer delays in women. Believing the symptoms would disappear or interpreting them as nothing serious were corresponding factors in men. In both genders bystanders acting by contacting EMS explained shorter prehospital delays.

Conclusions In STEMI, women differed from men in FMC and they had longer delays. This was partly due to atypical symptoms and a longer decision time. Bystanders acted more promptly when men than when women fell ill. Public knowledge of Ml symptoms, and how to act properly, still seems insufficient.

\section{INTRODUCTION}

Myocardial infarction (MI) mortality has decreased substantially during the last

\section{Strengths and limitations of this study}

- The present study is, to the best of our knowledge, the first published study of gender disparities and first medical contact in ST-elevation myocardial infarction (STEMI), using self-reported data covering symptoms, multiple time point measurements and actions, and self-reported reasons for delay and interpretation of symptoms as explanatory factors for prehospital delay.

- With the use of wide inclusion criteria, approximately $1 / 10$ of the hospitalised Swedish patients with STEMI during the inclusion period filled in the questionnaire within 24 hours of admittance, making the results generalisable and with limited risk of recall bias.

- Regarding the observational study design, we can only report associations rather than causations, and there may be factors associated with prehospital delay times not covered by the questionnaire, such as health literacy and deeper knowledge about Ml.

- Patients not being pain free and haemodynamically stable were excluded from participation, but we do not have any demographic data on this cohort, making it impossible to compare those participating in the study with those excluded.

- We have not collected data on all traditional risk factor variables (such as history of hypercholesterolaemia) which can be seen as a limitation.

decades in the Western world, because of more active prevention and better treatment. ${ }^{1}$ Still, outcomes in ST-elevation MI (STEMI) differ between the genders, with approximately two times as high in-hospital mortality in women, ${ }^{23}$ who receive reperfusion therapy less often than men. ${ }^{24}$ In STEMI, timely administration of reperfusion therapy is critical for improving survival. ${ }^{56}$ During the last decades, focus has mainly been on shortening system delay times where a clear association between longer delay and worse prognosis has been found. ${ }^{5}$ Consequently, 
STEMI guidelines strongly recommend that the diagnosis is made already in the prehospital setting. ${ }^{7}$ In Sweden, an ECG is taken by the Emergency Medical Services (EMS) paramedics in patients with symptoms indicating an evolving MI. The ECG is then transferred to the nearest hospital where the cardiologist/internist on call judges if the patient has a probable STEMI or not. Thus, in patients calling EMS, the diagnosis of STEMI can be made well in advance before admission to hospital and the patient can be directed straight to the catheterisation laboratory or could be given prehospital fibrinolytics. ${ }^{8}$

Less focus has been on the patient delay in the prehospital phase, which has been proven difficult to influence. ${ }^{910}$ The prehospital delay times have been unchanged over the past decades, ${ }^{11-13}$ but it is unknown whether the delay is due to difficulty with symptom recognition, symptom interpretation or decisions related to care seeking (including the mode of transportation to the hospital). In order to distinguish patient delay from system delay times, it has been suggested to also include the time point of first medical contact (FMC) in the analysis of prehospital delay times. ${ }^{14}$ However, previous studies have mostly focused on total prehospital delay times. ${ }^{11} 1215$ Since patients with STEMI do not always call EMS as their FMC, studying the different phases of prehospital delay times as well as choice of FMC is imperative. Female gender has been found to be associated with prehospital delay times according to several studies, ${ }^{12}{ }^{16-19}$ but measurements have been inconsistent ${ }^{20}$ and data on gender disparities on FMC in STEMI are very sparse. Consequently, further studies are needed to better understand the relation between gender and care-seeking behaviour in a STEMI population.

\section{Aim of the study}

We aimed to compare gender disparities in STEMI regarding: (1) FMC, (2) prehospital delay times from symptom onset to FMC as well as from symptom onset to diagnostic ECG and (3) factors associated with symptom onset to FMC in men and women separately.

\section{METHOD}

This Swedish multicentre study (SymTime) has been previously described. ${ }^{21}$ In short, it has a descriptive and comparative cross-sectional design of self-reported data. A previously validated self-administered questionnaire developed and tested in a Swedish chest pain population was used, ${ }^{22}$ with some minor changes and clarifications. The questionnaire covers 35 items including (1) baseline characteristics, (2) symptoms, (3) course of events including multiple time point measurements and (4) description of transport mode. We enrolled participants from five Swedish hospitals with diverged geographical locations, all with catheterisation facilities and primary percutaneous coronary intervention (PCI) enabled 24/7. Data were collected in the cardiac care unit in each participating hospital from November 2012 to January 2014. Eligible patients were planned to be consecutively included within 24 hours after admittance and were invited to answer the questionnaire after the primary PCI/reperfusion therapy had been given. Inclusion criteria were: (1) a confirmed STEMI diagnosis, (2) ability to fill in the questionnaire and(3) willingness to participate. Patients were pain free and haemodynamically stable when they were asked to participate and fill in the questionnaire. The staff nurse simultaneously obtained clinical data such as information on diagnosis, FMC, important time point measurements (eg, ECG and FMC) and comorbidities from the patients as well as from the medical records.

In this study, two parts of prehospital delay times were studied: (1) the interval between time of symptom onset to FMC and (2) the interval from symptom onset to diagnostic ECG. FMC was defined as the time point when contacting any healthcare personnel either by phone or in person and was divided into five possible contacts: (1) the primary healthcare centre (PHC) by phone, (2) the PHC directly, (3) the Swedish Healthcare Direct (SHD) by phone (ie, advisory nurses), (4) the EMS by phone or (5) the emergency room (ER) directly. All patients chose any of these five ways of contacting the Swedish healthcare system.

\section{Ethical aspects}

The study complied with the Declaration of Helsinki. ${ }^{23}$ Informed consent was obtained from all included patients.

\section{Patient and public involvement}

We originally involved patients in the development and the revision of the questionnaire used in this study when testing the user-friendliness and content in the modified questionnaire. The knowledge gain from this project will be disseminated to the public at different meeting and seminars at local patient organisations in Sweden. Participants interesting in the results have been advised to contact the study coordinator for information.

\section{Statistical analysis}

We used frequencies and proportions to describe the history of patients' characteristics, the sociodemographic, clinical and contextual variables and their FMC. Categorical variables were reported by numbers and percentages and groups were compared with the use of the $\mathrm{X}^{2}$ test. Continuous variables were reported as mean $\pm \mathrm{SD}$ or as medians with IQR, and gender comparisons were made with the two-tailed Student's t-test or the Mann-Whitney $\mathrm{U}$ test depending on if the variable was normally distributed or not. Multiple linear regression analyses were performed in men and women separately in order to sort out relevant predictors of patient delay. The time variable had to be log transformed in order to be normally distributed. Background characteristics, clinical presentation, context when falling ill, thoughts and actions as well as reactions from bystanders were included in five blocks in order to analyse the relevance of each block 


\begin{tabular}{|c|c|c|c|}
\hline & Men, $\mathrm{n}=340$ & $\begin{array}{l}\text { Women, } \\
n=109\end{array}$ & $P$ values \\
\hline \multicolumn{4}{|c|}{ Sociodemographic variables } \\
\hline Age, mean (SD) & $64.5(11.0)$ & $69.8(10.7)$ & $<0.001$ \\
\hline $\begin{array}{l}\text { Education level, } \\
\text { compulsory school }\end{array}$ & $120(35.3)$ & $53(48.6)$ & 0.02 \\
\hline Marital status, single & $68(20.0)$ & 34 (31.2) & 0.02 \\
\hline \multicolumn{4}{|l|}{ Clinical variables } \\
\hline Current smoker & $87(25.6)$ & 34 (31.2) & 0.25 \\
\hline Hypertension & $162(47.6)$ & $68(62.4)$ & 0.007 \\
\hline Diabetes & 46 (13.5) & $24(22.0)$ & 0.03 \\
\hline $\begin{array}{l}\text { Previous myocardial } \\
\text { infarction }\end{array}$ & $44(12.9)$ & $16(14.7)$ & 0.64 \\
\hline LAD as culprit artery & $144(42.4)$ & $42(38.5)$ & 0.48 \\
\hline
\end{tabular}

Missing values, none.

$L A D$, left artery descending.

in terms of $\mathrm{R}^{2}$ change. Residual plots were run, and no violations of assumptions were noted. Included variables were chosen through literature research and/or deemed to be important by the research group. There were few missing values in the data collection- regarding the most important outcome measurements there were no (symptoms) or minor (FMC, $0.9 \%$ and delay from symptom onset until FMC, 3.8\%) missing values. All tests were two tailed and a p value of less than 0.05 was deemed as indicating a statistically significant difference between compared groups. All statistical analyses were performed using IBM SPSS Statistics V.23.0 (SPSS) for Windows.

\section{RESULTS}

\section{Background characteristics and clinical presentation}

In total, 449 patients with STEMI were included. Women were 5 years older than men, with lower educational status and more often living on their own. Women had a higher prevalence of hypertension as well as diabetes mellitus (table 1). Among chief complaints, chest pain/discomfort was prevalent in $92 \%$ of men compared with $73 \%$ of women, $\mathrm{p}<0.001$. Pain in the throat/neck, back and/or shoulder was two times as common in women as in men, as well as a feeling of fear. Nausea was prevalent in half of the women compared with one-third of the men. There was no gender difference in pain intensity (table 2).

\section{Thoughts, actions and context when falling ill}

When falling ill in STEMI, women were more often together with their children, relatives or friends, whereas men were more often together with colleagues. There was no gender difference in being alone or being at home at the time. Self-medication with aspirin was as common in both genders as well as nitroglycerine, whereas women took painkillers almost two times as often as men $(27 \%$ vs $15 \%, \mathrm{p}<0.01)$. The first person to talk to about the

\begin{tabular}{|c|c|c|c|}
\hline & Men, $\mathrm{n}=340$ & $\begin{array}{l}\text { Women, } \\
n=109\end{array}$ & $P$ values \\
\hline \multicolumn{4}{|c|}{ Pain/pressure/discomfort in } \\
\hline Chest/thorax & $313(92.1)$ & 80 (73.4) & $<0.001$ \\
\hline Throat/neck & $57(16.8)$ & $40(36.7)$ & $<0.001$ \\
\hline Back & $42(12.4)$ & $32(29.4)$ & $<0.001$ \\
\hline Stomach & $30(8.8)$ & $6(5.5)$ & 0.27 \\
\hline Shoulders & $53(15.6)$ & $36(33.0)$ & $<0.001$ \\
\hline Arms/hands & $183(53.8)$ & $71(65.1)$ & 0.04 \\
\hline \multicolumn{4}{|l|}{ Associated symptoms } \\
\hline Tiredness/fatigue & $102(30.0)$ & 45 (41.3) & 0.03 \\
\hline Nausea/vomiting & $94(27.6)$ & $53(48.6)$ & $<0.001$ \\
\hline Cold sweat & 197 (57.9) & $70(64.2)$ & 0.25 \\
\hline Fear & $57(16.8)$ & 34 (31.2) & 0.001 \\
\hline \multicolumn{4}{|l|}{ Symptom intensity } \\
\hline $\begin{array}{l}\text { Pain intensity, NRS, } \\
\text { median (IQR) }\end{array}$ & $7(6.8)$ & $7(6.8)$ & 0.65 \\
\hline
\end{tabular}

$3(<1 \%)$ patients did not grade any pain/discomfort on the NRS. No missing values regarding other variables.

NRS, Numeric Rating Scale.

symptoms was the partner, which was the case in more than half of both men and women. Women more often than men informed their children first of all about their symptoms, whereas men more often than women first talked to friends or relatives. More than one-third of the women compared with one-fourth of the men spoke to the SHD before they went to the hospital (28\% vs $18 \%$, $\mathrm{p}=0.02$ ) and less than one-fifth of both men and women talked to their PHC, with no difference between the genders. To a great extent both genders had heard of angioplasty or clot dissolving as treatment for MI.

The most common reason why patients with STEMI went to the hospital was severe symptoms, with no difference between the genders. Men went to hospital because of believing they were struck by an MI to a higher extent compared with women (25\% vs $15 \%, \mathrm{p}=0.04)$. There was neither any gender difference in hesitating going to the hospital, nor in reasons why hesitating. The most common reason for why hesitating was a belief the symptoms would disappear, with no difference between the genders (table 3 ).

\section{Reactions from bystanders}

Men were more often recommended to call 112 by bystanders $(38 \%$ vs $22 \%, \mathrm{p}<0.01)$. Women more often had bystanders calling SHD ( $36 \%$ vs $25 \%, \mathrm{p}=0.03$ ), but also more often did not tell anyone about their symptoms ( $7 \%$ vs $2 \%, \mathrm{p}=0.02)$ (table 4$)$.

\section{Delay times and FMC}

In the total study population, the median patient delay from symptom onset to FMC was $70 \mathrm{~min}$ (IQR 30-178) 
Table 3 Thoughts, actions and context when falling ill with STEMI

\begin{tabular}{|c|c|c|c|}
\hline & Men, $n=340$ & Women, $\mathrm{n}=109$ & P values \\
\hline \multicolumn{4}{|l|}{ With whom did you first talk about your symptoms? } \\
\hline My wife/husband/partner & $202(60.3)$ & $60(55.6)$ & 0.38 \\
\hline A relative or friend & $31(9.3)$ & $3(2.8)$ & 0.03 \\
\hline My children & $23(6.9)$ & $18(16.7)$ & 0.002 \\
\hline The SHD & $11(3.3)$ & $7(6.5)$ & 0.14 \\
\hline The emergency medical service & $20(6.0)$ & $4(3.7)$ & 0.36 \\
\hline The PHC & $15(4.5)$ & $5(4.6)$ & 0.95 \\
\hline Someone else & $30(9.0)$ & $11(10.2)$ & 0.70 \\
\hline \multicolumn{4}{|c|}{ Did you call any of the following before you went to the hospital? } \\
\hline The PHC & $66(19.8)$ & $17(15.6)$ & 0.33 \\
\hline The SHD & $81(24.3)$ & $33.9(37)$ & 0.05 \\
\hline \multicolumn{4}{|c|}{ Did you take any medication in order to relieve the symptoms? } \\
\hline Painkillers & $50(14.7)$ & $29(26.6)$ & 0.005 \\
\hline Nitroglycerine & $44(12.9)$ & $20(18.3)$ & 0.16 \\
\hline \multicolumn{4}{|c|}{ Have you heard of angioplasty or clot-dissolving treatment in case of MI? } \\
\hline Yes, I have & $319(94.1)$ & $99(93.4)$ & 0.79 \\
\hline \multicolumn{4}{|l|}{ Why did you decide to go to the hospital? } \\
\hline The symptoms were severe & $108(33.9)$ & $36(34.3)$ & 0.94 \\
\hline I thought I had an MI & $79(24.8)$ & $16(15.2)$ & 0.04 \\
\hline $\begin{array}{l}\text { I was told to seek care by my wife/husband/ } \\
\text { partner }\end{array}$ & $38(11.9)$ & $14(13.3)$ & 0.70 \\
\hline Another reason for going to the hospital & $22(6.9)$ & $12(11.4)$ & 0.14 \\
\hline \multicolumn{4}{|c|}{ Did you hesitate to go to the hospital? If yes, why? } \\
\hline I did not hesitate & $249(73.5)$ & $74(67.9)$ & 0.26 \\
\hline I thought the symptoms would disappear & $85(25.1)$ & $31(28.4)$ & 0.49 \\
\hline I did not think it was anything serious & $27(8.9)$ & $8(7.3)$ & 0.83 \\
\hline I did not want to worry my family & $17(5.0)$ & $5(4.6)$ & 0.86 \\
\hline I did want to draw attention & $4(1.2)$ & $2(1.8)$ & 0.61 \\
\hline I did not want to disturb anyone & $10(2.9)$ & $3(2.8)$ & 0.92 \\
\hline I felt discomfort in facing being hospitalised & $11(3.2)$ & $5(4.6)$ & 0.51 \\
\hline \multicolumn{4}{|l|}{ Context when falling ill } \\
\hline At home & $253(74.4)$ & $90(82.6)$ & 0.08 \\
\hline I was alone & $91(26.8)$ & $29(26.6)$ & 0.97 \\
\hline Weekend & $95(29.3)$ & $34(31.8)$ & 0.49 \\
\hline Weekdays, out of office time & $118(35.4)$ & $38(35.8)$ & 0.94 \\
\hline \multicolumn{4}{|l|}{ Transport mode } \\
\hline I went by ambulance to the hospital & $280(82.4)$ & $91(83.5)$ & 0.79 \\
\hline
\end{tabular}

Missing values; 25 (5.6\%) patients did not answer the question about why hesitating before going to the hospital. No, or minor, details missing regarding all other variables.

MI, myocardial infarction; PHC, primary healthcare centre; SHD, Swedish Healthcare Direct; STEMI, ST-elevation myocardial infarction.

and to diagnostic ECG $110 \mathrm{~min}$ (IQR 64-238). The system delay from FMC to diagnostic ECG was $27 \mathrm{~min}$ (IQR 15-50). Women waited in median $90 \mathrm{~min}$ (IQR 39-221) before taking their FMC compared with $66 \mathrm{~min}$ (IQR 28-161) in men, $p=0.04$. EMS was the most common FMC used by approximately half of the patients regardless of sex, but women more often contacted SHD as FMC compared with men, $28 \%$ vs $18 \%(\mathrm{p}=0.02)$ (figure 1 ). After being urged to contact the EMS by the general practitioner (GP) or the advisory nurse at the SHD, $83 \%$ of patients finally arrived at the hospital by ambulance while the remainder transported themselves directly to the ER. 
Table 4 Reactions from bystanders when a person fell ill

\begin{tabular}{|c|c|c|c|}
\hline & $\begin{array}{l}\text { Men } \\
\mathrm{n}=340\end{array}$ & $\begin{array}{l}\text { Women } \\
n=109\end{array}$ & $P$ values \\
\hline $\begin{array}{l}\text { He/she/they suggested } \\
\text { that I should rest }\end{array}$ & $47(14.0)$ & $13(12.0)$ & 0.61 \\
\hline $\begin{array}{l}\text { He/she/they suggested } \\
\text { medication }\end{array}$ & $11(3.3)$ & $7(6.5)$ & 0.14 \\
\hline $\begin{array}{l}\text { He/she/they suggested } \\
\text { that I should call EMS }\end{array}$ & $126(37.5)$ & $24(22.2)$ & 0.003 \\
\hline $\begin{array}{l}\text { He/she/they suggested } \\
\text { that I should call SHD }\end{array}$ & $85(25.3)$ & $85(78.7)$ & 0.40 \\
\hline $\mathrm{He} /$ she/they called EMS & $175(52.1)$ & $55(51.4)$ & 0.90 \\
\hline $\mathrm{He} /$ she/they called SHD & $85(25.3)$ & $39(36.1)$ & 0.03 \\
\hline $\begin{array}{l}\text { He/she/they brought me } \\
\text { to the hospital }\end{array}$ & 63 (18.8) & $23(21.3)$ & 0.56 \\
\hline I did not tell anyone & $8(2.4)$ & $8(7.4)$ & 0.02 \\
\hline
\end{tabular}

Missing values; 5 (1.1\%) patients did not answer question about reactions from bystanders.

EMS, emergency medical services; SHD, Swedish Healthcare Direct.

System delay time in form of FMC to diagnostic ECG did not differ between the genders, (25 (15-49) min in men vs 33 (15-61) $\mathrm{min}$ in women, $\mathrm{p}=0.09)$. Altogether, women had a longer delay from symptom onset to diagnostic ECG (146 (68-316) $\mathrm{min}$ in women, vs 103 (61-221) min in men $\mathrm{p}=0.03)$. Divided in subgroups on short, medium and long delay, women more often had a long delay compared with men, both from symptom onset to FMC, and from symptom onset to diagnostic ECG (figures 2-4).

\section{Factors associated with delay in men and women}

In women, sociodemographic, contextual, cognitive, behavioural and clinical factors included in the survey explained $53 \%$ of the variance of prehospital delay times from symptom onset to FMC compared with $26 \%$ in men (ie, the $\mathrm{R}^{2}$ for the complete model, men and women studied separately). In both genders, the clinical presentation explained most of the delay from symptom onset to FMC, followed by thoughts and actions when falling ill. In women hesitating to go to the hospital, stomach pain and pain in the back/shoulders were the variables most strongly associated with increased delay, while cold sweat and bystanders calling-or recommending calling-EMS were the variables most strongly associated with short delay. In men, believing the symptoms would disappear or interpreting the symptoms as nothing serious had the strongest association with increased delay, whereas bystanders calling EMS was the variable most strongly associated with reduced delay (table 5).

\section{DISCUSSION}

The main findings of the present study are the far longer delay times in women versus men among Swedish patients with STEMI, from symptom onset to FMC of $26 \mathrm{~min}$ and from symptom onset to diagnostic ECG of $43 \mathrm{~min}$. This was due to primarily three factors: (1) more atypical symptoms in women and (2) a longer decision time in women and (3) a gender difference in choice of FMC, where women more often than men called the national SHD service number for advice.

Prehospital delay times account for the largest proportion of the total ischaemic time $\mathrm{e}^{9}$ but have remained virtually unchanged over the last decades. ${ }^{12}$ This is important since only patients with STEMI with a short prehospital delay $(<90 \mathrm{~min})$ have a long-term benefit of shorter system delay to reperfusion. ${ }^{24}$ Although interventions aimed at shortening prehospital delay times have been discouraging, ${ }^{910}$ a more recent report from Denmark on patients with STEMI calling EMS services have found a temporal trend of decrease in prehospital delay times (symptom-onset-to-calling EMS) from 101 to $85 \mathrm{~min}$ between year 2003 and 2009. This was after introduction of primary PCI to all patients with STEMI, which the
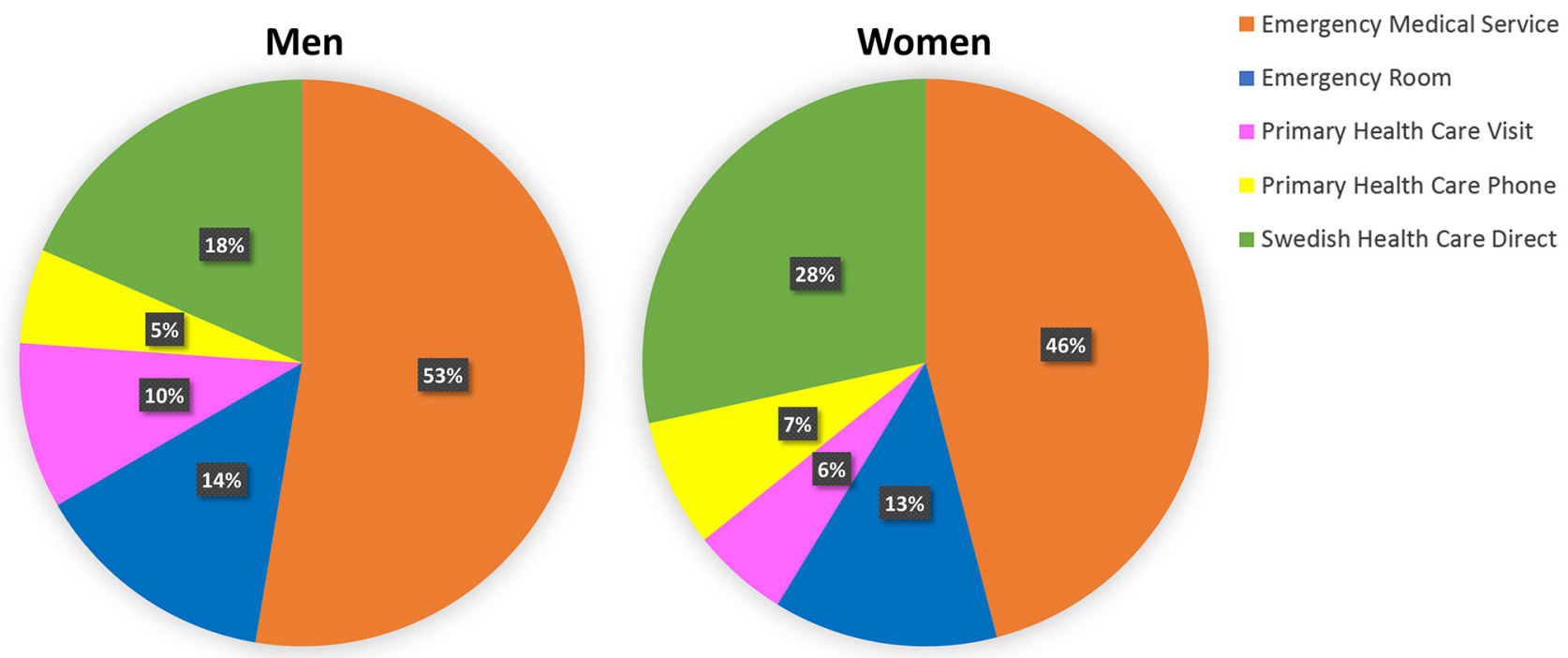

Figure 1 First medical contact in men and women with ST-elevation myocardial infarction. 


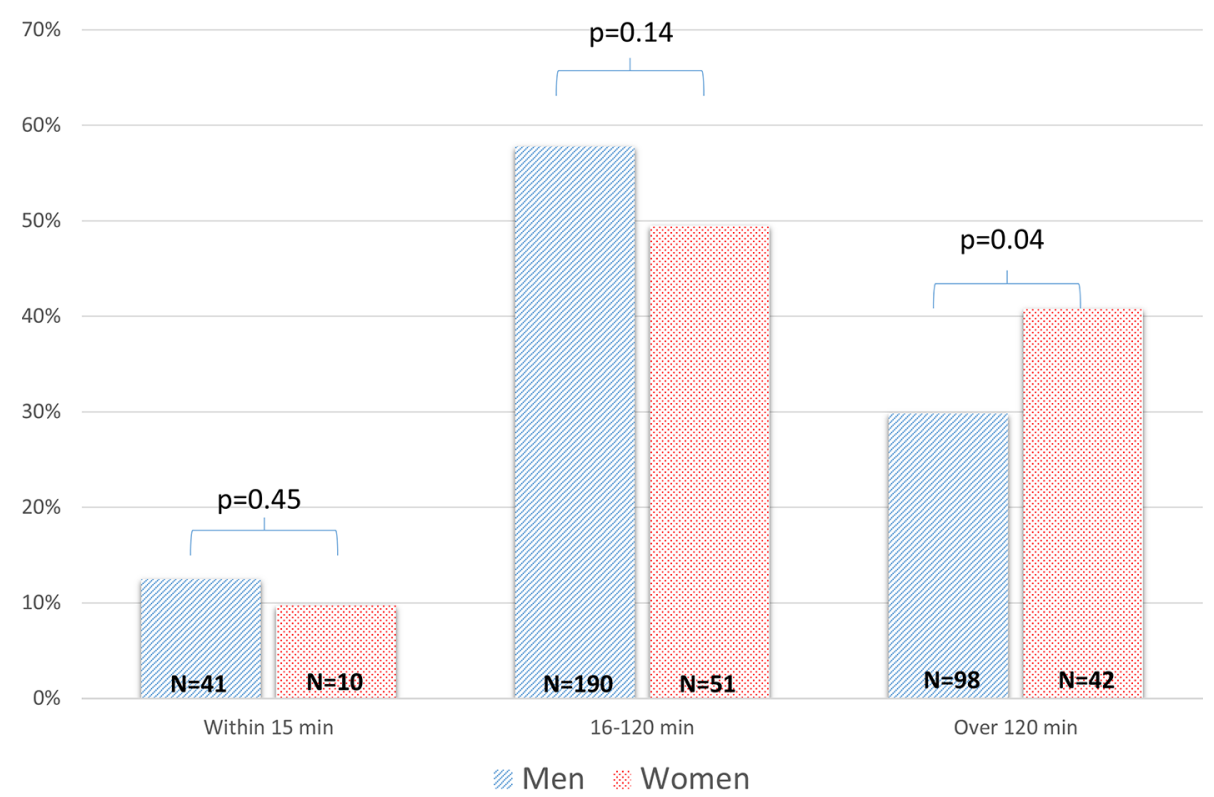

Figure 2 Delay times from symptom onset to first medical contact.

authors claim could have had potentially positive effects on public awareness. ${ }^{25}$ Still, further efforts are needed in order to increase public awareness and in the recent scientific statements from the American Heart Association, the authors emphasise improved methods to disseminate information about women's risks, symptoms, and behaviours and necessary responses to symptoms of acute MI. ${ }^{19}$

Few studies have focused on delays to FMC in STEMI. The majority of previous studies have defined prehospital delay time as the time interval from symptom onset to hospital arrival, without separating the patient from the system delay, that is, before and after FMC. ${ }^{11} 12152627$ However, in a recent registry-based study, Bugiardini $e t$ $a l^{28}$ report time lapses from symptom onset to calls to EMS or a GP's office and found no significant time differences among men and women (50 min vs $60 \mathrm{~min}$ ) while we did find a significant delay between genders ( 66 min delay in men vs $90 \mathrm{~min}$ in women). Still, the time lapses are not completely comparable since our FMC, beyond calls to the EMS and the GP's office, also included in-office visits to the GP, a phone contact with an advisory nurse or a direct contact with the ER. Studies on gender disparities in prehospital delay times have shown inconsistent results and have limitations such as using restricted patient samples, ${ }^{26}$ or relying primarily on information from medical records ${ }^{26}$ or registries not specifically designed to study delay. ${ }^{1126} 27$ Finally, many studies have included mixed patients with MI not restricting the inclusion to STEMI. ${ }^{1122}{ }^{26}$ In the current study focusing on patient

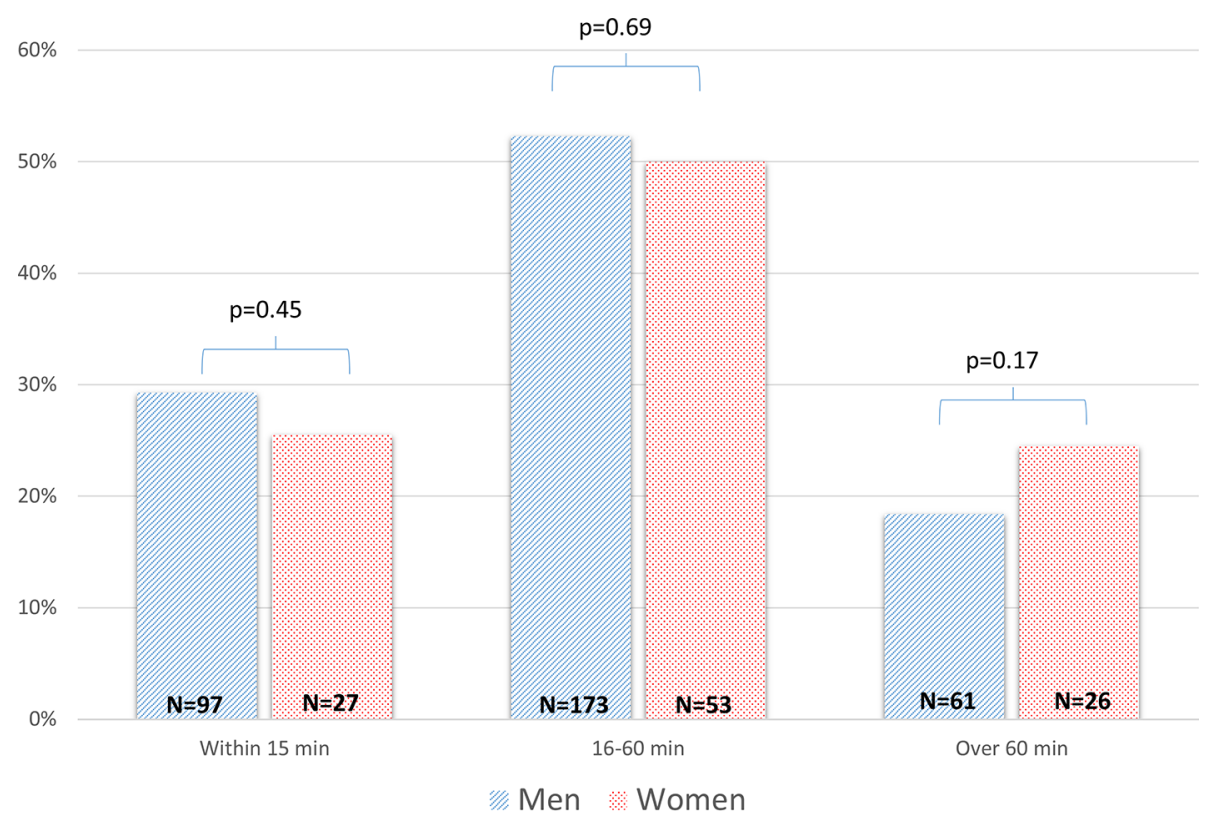

Figure 3 Delay times from first medical contact until diagnosis. 
$p=0.35$

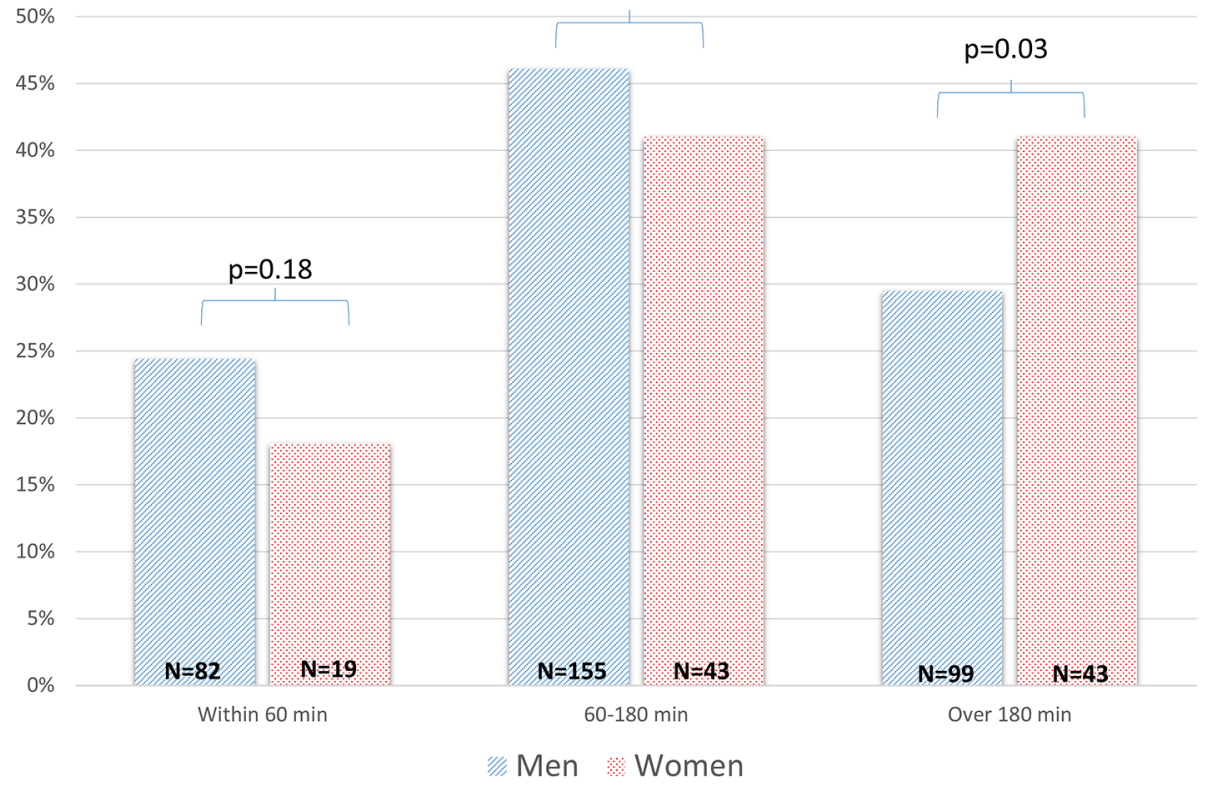

Figure 4 Delay times from symptom onset to diagnosis.

delay from symptom onset to FMC and from symptom onset to diagnosis of STEMI, women delayed 1.5 hours until FMC compared with approximately 1 hour in men. In the total study population, the median delay from symptom onset to FMC of $70 \mathrm{~min}$, and to diagnostic ECG of $110 \mathrm{~min}$, is substantially better than reported in studies from other American and European countries ${ }^{18} 2829$ but still exceeding the recommendations advised by guidelines by several minutes. ${ }^{30}$ A study based on the French eMUST registry, including patients with STEMI who have been taken care of by special mobile intensive care units, found in accordance with our data that women waited longer before calling the EMS. They also found a very similar delay until calling as we did to any FMC (78 min in women vs $54 \mathrm{~min}$ in men, $\mathrm{p}<0.0001) .{ }^{18}$ In the present study, more than $40 \%$ of the women compared with $30 \%$ of the men waited over 2 hours before seeking medical attention. Reducing patient-caused delay has a great potential to improve the outcomes of patients with STEMI, given that many deaths occur early after symptom onset.

It is important to analyse care-seeking behaviour in different regions of the world, as differences in medical insurance and healthcare systems do play a part as well as cultural factors and gender equality reflecting differences in awareness, interpretation and actions on MI symptoms. In Sweden, counted as one of the most gender equal countries in the world, with complete healthcare coverage for all citizens, only small gender disparities were found in context, thoughts and actions when falling ill. Men more often first talked about their symptoms with a spouse, relative or friend whereas women more often talked with their child/children. This probably reflects the fact that women are older than men when falling ill with STEMI, and thus more often living on their own because of being widowed. ${ }^{31}$ Older studies from other geographical regions have found that "not wanting to trouble anyone' is a factor associated with prolonged delay in women, but not in men. ${ }^{32}$ In the present study, no difference was found as regards worries of disturbing or drawing attention.

Women and men differed in FMC in the current study. EMS was the FMC in only half of the patients $(53 \%$ of men and $46 \%$ of women) and instead as many as one in three of the women and one in five of the men called SHD as the FMC despite suffering from a very serious disease. In Sweden, SHD—a joint service number-was launched in 2003 and is staffed by advisory nurses $24 / 7$ in order to answer questions, determine the need for further care and provide advice and/or contact with other healthcare providers. SHD has become a very important way of contacting the healthcare system and gets around 500000 calls every month. The use of SHD in STEMI is worrying as we have shown in a previous study that patients turning to SHD as FMC had a 38 min longer delay from symptom onset until first ECG compared with patients calling EMS. ${ }^{21}$ The reluctance to call EMS may be explained by several factors such as misinterpretation of symptoms, as well as women's lack of perceived potential risk for acute coronary syndrome (ACS) ${ }^{33}$ The women in our study were less educated than the men and in the multivariable analysis, this variable tended to be associated with longer prehospital delay times in women $(\mathrm{p}=0.06)$. This could be attributed to low socioeconomic status and lack of ACS knowledge in women. ${ }^{19}$ Anyhow, it is reassuring that although far too few patients, both men and women chose EMS as FMC, $83 \%$ of patients finally arrived at the hospital by ambulance while the remainder transported themselves directly to the ER. We have previously shown that this was the case regardless of if the patient chose calling/visiting PHC, calling EMS or calling SHD as their FMC. $^{21}$ 
Table 5 Predictions of patient delay times in men and women separately

\begin{tabular}{|c|c|c|c|c|c|c|}
\hline & \multicolumn{3}{|l|}{ Men, $n=340$} & \multicolumn{3}{|l|}{ Women, $n=109$} \\
\hline & $\begin{array}{l}\text { Standardised } \\
\text { beta }\end{array}$ & $P$ values & $R^{2}$ change & $\begin{array}{l}\text { Standardised } \\
\text { Beta }\end{array}$ & $P$ values & $\mathbf{R}^{2}$ change \\
\hline Block 1: background characteristics & & & 0.04 & & & 0.13 \\
\hline Age & 0.12 & 0.05 & & 0.07 & 0.54 & \\
\hline Current smoker & 0.14 & 0.01 & & 0.19 & 0.05 & \\
\hline Block 2: symptoms & & & 0.10 & & & 0.23 \\
\hline Chest pain & 0.15 & 0.01 & & 0.05 & 0.55 & \\
\hline Pain in back/shoulders & -0.03 & 0.60 & & 0.25 & 0.01 & \\
\hline Stomach pain & 0.09 & 0.07 & & 0.30 & 0.00 & \\
\hline Cold sweat & -0.07 & 0.19 & & -0.18 & 0.04 & \\
\hline Anguish/fear & -0.13 & 0.01 & & -0.08 & 0.38 & \\
\hline Block 3: context when falling ill & & & 0.02 & & & 0.08 \\
\hline At home & -0.11 & 0.03 & & -0.04 & 0.62 & \\
\hline Out of office time & 0.06 & 0.27 & & 0.18 & 0.03 & \\
\hline Block 4: reactions from bystanders & & & 0.08 & & & 0.12 \\
\hline They suggested rest & -0.13 & 0.02 & & 0.10 & 0.28 & \\
\hline They suggested calling EMS & -0.04 & 0.41 & & -0.22 & 0.02 & \\
\hline They called EMS & -0.28 & 0.00 & & -0.23 & 0.01 & \\
\hline They drove me to the hospital & 0.02 & 0.75 & & -0.14 & 0.12 & \\
\hline Block 5: thoughts and actions & & & 0.09 & & & 0.13 \\
\hline $\begin{array}{l}\text { I took some medication to relieve the } \\
\text { symptoms }\end{array}$ & 0.12 & 0.03 & & 0.06 & 0.47 & \\
\hline I hesitated about going to the hospital & -0.11 & 0.26 & & 0.62 & 0.00 & \\
\hline $\begin{array}{l}\text { I thought the symptoms would go } \\
\text { away/it was not anything serious }\end{array}$ & 0.25 & 0.01 & & -0.31 & 0.06 & \\
\hline I did not want to worry my relatives & 0.09 & 0.11 & & -0.17 & 0.05 & \\
\hline $\begin{array}{l}\text { I was afraid of the reaction from the } \\
\text { hospital staff }\end{array}$ & 0.05 & 0.34 & & 0.20 & 0.04 & \\
\hline
\end{tabular}

Multiple linear regression with log-transformed prehospital delay time from symptom onset to first medical contact in minutes as the dependent variable. Independent variables entered in five blocks, significant predictors in the multivariable analyses shown in table. $R^{2}$ for the complete model 0.53 in women, 0.26 in men.

EMS, emergency medical service.

A large gender disparity in chest pain prevalence-the most well-recognised symptom of MI presentation in society-was found. The fact that women are less likely to experience chest pain has also been noted in two recent scientific statements from the American Heart Association ${ }^{1931}$ and is in accordance with a previous large registry study in a mixed MI population. ${ }^{34}$ At the same time less well-known MI symptoms such as pain in the neck, throat, back or shoulders or nausea were more than two times as common in women as in men. Previous studies have found that MI symptoms looked on as typical such as chest pain or pain in the left arm are most important for a correct attribution to the heart ${ }^{35}$ and that the prognosis is worse in patients with MI with atypical symptoms. ${ }^{34} \mathrm{In}$ accordance, men more often than women responded that believing that they had an MI was the reason for going to the hospital in the current study. The importance of the clinical presentation for patient delay was shown in the multivariable regression with the presence of symptoms such as pain in the back, shoulders or stomach being associated with longer delay in women but not in men. Symptoms that are perceived as threatening have been described associated with shorter prehospital delay times. ${ }^{36}$ Accordingly, in the present study, cold sweat was associated with shorter delay in women and anguish/fear was associated with shorter delay in men.

Finally, bystanders can be crucial in obtaining appropriate care. In the present study, bystanders calling EMS was one of the strongest factors associated with short delay although a gender difference in bystanders' responses to described symptoms depending on the patient's gender was found-whereas men more often had bystanders recommending contact with the EMS, women more often had bystanders calling SHD for advice. A previous study 
has found that relatives are more dissatisfied with the information given by the hospital staff compared with the patient. ${ }^{37}$ This illustrates the need to involve the next of kin in secondary prevention education and care-seeking behaviour, as a well-informed bystander can help diminish the patients' decision time.

\section{CONCLUSION}

In conclusion, this study showed that women differ from men regarding several self-reported symptoms, thoughts, actions and prehospital delay times-and partly also in reasons as to why delaying. Based on our findings, women may have different educational needs compared with men, which has to be considered when educating the public about how to recognise and act when an evolving MI emerges.

Acknowledgements The authors hereby acknowledge all participating hospitals and their staff who included patients on a daily basis, making this project possible. We especially acknowledge Elisabeth Logander, a highly skilled research nurse at Linköping University Hospital, who supported the study group throughout the project.

Contributors SSL and IT contributed to the study planning, design, preparation, validation of the slightly modified questionnaire and data analysis. KHÄ, ME and SSL contributed to the data collection. KHÄ, ME, R-MI, SSL and IT contributed to the manuscript preparation and approved the final version of the manuscript.

Funding This work was supported by the Medical Research Council of Southeast Sweden (FORSS), the County Council of Östergötland and the County Council of Norrbotten.

Competing interests None declared.

Patient consent Not required.

Ethics approval Permission for the study was obtained from the regional Ethical Review Board, Linköping, Sweden (D-nr 2012/201-31)

Provenance and peer review Not commissioned; externally peer reviewed.

Data sharing statement № additional data are available.

Open Access This is an Open Access article distributed in accordance with the Creative Commons Attribution Non Commercial (CC BY-NC 4.0) license, which permits others to distribute, remix, adapt, build upon this work non-commercially, and license their derivative works on different terms, provided the original work is properly cited and the use is non-commercial. See: http://creativecommons.org/ licenses/by-nc/4.0/

(C) Article author(s) (or their employer(s) unless otherwise stated in the text of the article) 2018. All rights reserved. No commercial use is permitted unless otherwise expressly granted.

\section{REFERENCES}

1. Schmidt M, Jacobsen JB, Lash TL, et al. 25 year trends in first time hospitalisation for acute myocardial infarction, subsequent short and long term mortality, and the prognostic impact of sex and comorbidity: a Danish nationwide cohort study. BMJ 2012;344:e356.

2. Lawesson SS, Alfredsson J, Fredrikson M, et al. Time trends in STEMI--improved treatment and outcome but still a gender gap: a prospective observational cohort study from the SWEDEHEART register. BMJ Open 2012;2:e000726.

3. Kytö V, Sipilä J, Rautava P. Gender and in-hospital mortality of ST-segment elevation myocardial infarction (from a multihospital nationwide registry study of 31,689 patients). Am J Cardiol 2015;115:303-6.

4. D'Onofrio G, Safdar B, Lichtman JH, et al. Sex differences in reperfusion in young patients with ST-segment-elevation myocardial infarction: results from the VIRGO study. Circulation 2015;131:1324-32.
5. Terkelsen CJ, Sørensen JT, Maeng M, et al. System delay and mortality among patients with STEMI treated with primary percutaneous coronary intervention. JAMA 2010;304:763-71.

6. De Luca G, Suryapranata H, Ottervanger JP, et al. Time delay to treatment and mortality in primary angioplasty for acute myocardial infarction: every minute of delay counts. Circulation 2004;109:1223-5.

7. Ibanez B, James S, Agewall S, et al. ESC Guidelines for the management of acute myocardial infarction in patients presenting with ST-segment elevation: The Task Force for the management of acute myocardial infarction in patients presenting with ST-segment elevation of the European Society of Cardiology (ESC). Eur Heart $J$ 2017:1-66

8. Uppsala Clinical Research Center. SWEDEHEART Annual report 2016. In: Martina Tillberg U, ed. SWEDEHEART Annual reports. Stockholm: Tomas Jernberg, Karolinska University Hospital, Uppsala Clinical Research Center, 2017.

9. Luepker RV, Raczynski JM, Osganian S, et al. Effect of a community intervention on patient delay and emergency medical service use in acute coronary heart disease: the Rapid Early Action for Coronary Treatment (REACT) Trial. JAMA 2000;284:60-7.

10. Dracup K, McKinley S, Riegel B, et al. A randomized clinical trial to reduce patient prehospital delay to treatment in acute coronary syndrome. Circ Cardiovasc Qual Outcomes 2009;2:524-32.

11. Goldberg RJ, Spencer FA, Fox KA, et al. Prehospital delay in patients with acute coronary syndromes (from the Global Registry of Acute Coronary Events [GRACE]). Am J Cardiol 2009;103:598-603.

12. Ladwig $\mathrm{KH}$, Meisinger $\mathrm{C}$, Hymer $\mathrm{H}$, et al. Sex and age specific time patterns and long term time trends of pre-hospital delay of patients presenting with acute ST-segment elevation myocardial infarction. Int J Cardiol 2011:152:350-5.

13. Spencer FA, Montalescot G, Fox KA, et al. Delay to reperfusion in patients with acute myocardial infarction presenting to acute care hospitals: an international perspective. Eur Heart $J$ 2010;31:1328-36.

14. Moser DK, Kimble LP, Alberts MJ, et al. Reducing delay in seeking treatment by patients with acute coronary syndrome and stroke: a scientific statement from the American Heart Association Council on cardiovascular nursing and stroke council. Circulation 2006;114:168-82.

15. Peng YG, Feng JJ, Guo LF, et al. Factors associated with prehospital delay in patients with ST-segment elevation acute myocardial infarction in China. Am J Emerg Med 2014;32:349-55.

16. Nguyen HL, Saczynski JS, Gore JM, et al. Age and sex differences in duration of prehospital delay in patients with acute myocardial infarction: a systematic review. Circ Cardiovasc Qual Outcomes 2010;3:82-92.

17. Ting $H H$, Chen AY, Roe MT, et al. Delay from symptom onset to hospital presentation for patients with non-ST-segment elevation myocardial infarction. Arch Intern Med 2010;170:1834-41.

18. Benamer $\mathrm{H}$, Bataille $\mathrm{S}$, Tafflet $\mathrm{M}$, et al. Longer pre-hospital delays and higher mortality in women with STEMI: the e-MUST Registry. Eurolntervention 2016;12:e542-e549.

19. McSweeney JC, Rosenfeld AG, Abel WM, et al. Preventing and experiencing ischemic heart disease as a woman: state of the science: a scientific statement from the american heart association. Circulation 2016;133:1302-31.

20. Mackay MH, Ratner PA, Nguyen M, et al. Inconsistent measurement of acute coronary syndrome patients' pre-hospital delay in research: a review of the literature. Eur J Cardiovasc Nurs 2014;13:483-93.

21. Thylén I, Ericsson M, Hellström Ängerud K, et al. First medical contact in patients with STEMI and its impact on time to diagnosis; an explorative cross-sectional study. BMJ Open 2015;5:e007059.

22. Johansson I, Strömberg A, Swahn E. Factors related to delay times in patients with suspected acute myocardial infarction. Heart Lung 2004;33:291-300.

23. World Medical A; World Medical Association. World medical association declaration of Helsinki: ethical principles for medical research involving human subjects. JAMA 2013;310:2191-4.

24. Brodie BR, Gersh BJ, Stuckey T, et al. When is door-to-balloon time critical? Analysis from the HORIZONS-AMI (Harmonizing Outcomes with Revascularization and Stents in Acute Myocardial Infarction) and CADILLAC (Controlled Abciximab and Device Investigation to Lower Late Angioplasty Complications) trials. J Am Coll Cardiol 2010;56:407-13.

25. Nielsen CG, Laut KG, Jensen LO, et al. Patient delay in patients with ST-elevation myocardial infarction: Time patterns and predictors for a prolonged delay. Eur Heart J Acute Cardiovasc Care 2017;6:583-91.

26. Ting HH, Bradley EH, Wang $\mathrm{Y}$, et al. Factors associated with longer time from symptom onset to hospital presentation for 
patients with ST-elevation myocardial infarction. Arch Intern Med 2008;168:959-68.

27. Lawesson SS, Alfredsson J, Fredrikson M, et al. A gender perspective on short- and long term mortality in ST-elevation myocardial infarction--a report from the SWEDEHEART register. Int $J$ Cardiol 2013;168:1041-7.

28. Bugiardini R, Ricci B, Cenko E, et al. Delayed care and mortality among women and men with myocardial infarction. J Am Heart Assoc 2017;6:e005968.

29. Pfister R, Lee S, Kuhr K, et al. Impact of the type of first medical contact within a guideline-conform ST-Elevation myocardial infarction network: a prospective observational registry study. PLoS One 2016;11:e0156769.

30. O'Gara PT, Kushner FG, Ascheim DD, et al. 2013 ACCF/AHA guideline for the management of ST-elevation myocardial infarction: executive summary: a report of the American College of Cardiology Foundation/American Heart Association Task Force on Practice Guidelines. Circulation 2013;127:529-55.

31. Mehta LS, Beckie TM, DeVon HA, et al. Acute myocardial infarction in women: a scientific statement from the american heart association. Circulation 2016;133:916-47.
32. Moser DK, McKinley S, Dracup K, et al. Gender differences in reasons patients delay in seeking treatment for acute myocardial infarction symptoms. Patient Educ Couns 2005;56:45-54.

33. Sjöström-Strand A, Fridlund B. Women's descriptions of symptoms and delay reasons in seeking medical care at the time of a first myocardial infarction: a qualitative study. Int J Nurs Stud 2008;45:1003-10.

34. Canto JG, Rogers WJ, Goldberg RJ, et al. Association of age and sex with myocardial infarction symptom presentation and in-hospital mortality. JAMA 2012;307:813-22.

35. Kirchberger I, Heier M, Kuch B, et al. Sex differences in patientreported symptoms associated with myocardial infarction (from the population-based MONICA/KORA Myocardial Infarction Registry). Am J Cardiol 2011;107:1585-9.

36. Ängerud $\mathrm{KH}$, Brulin $\mathrm{C}$, Näslund $\mathrm{U}$, et al. Longer pre-hospital delay in first myocardial infarction among patients with diabetes: an analysis of 4266 patients in the northern Sweden MONICA Study. BMC Cardiovasc Disord 2013;13:6.

37. Henriksson C, Larsson M, Arnetz J, et al. Knowledge and attitudes toward seeking medical care for AMI-symptoms. Int J Cardiol $2011 ; 147: 224-7$ 